\title{
Revista Brasileira de Educação Física: a Moderna Ginástica Sueca no Brasil (1944-1952) ${ }^{1}$
}

\author{
Brazilian Journal of Physical Education: \\ Modern Swedish Gymnastics in Brazil (1944-1952) \\ Revista brasileña de educación física: \\ la moderna gimnasia sueca en Brasil (1944-1952) \\ Anderson Cunha Baía \\ Universidade Federal de Viçosa (Brasil) \\ https://orcid.org/0000-0002-7363-689X \\ http://lattes.cnpq.br/4790819454267242 \\ andersonbaia@yahoo.com.br \\ Andrea Moreno \\ Universidade Federal de Minas Gerais (Brasil) \\ https://orcid.org/0000-0002-3371-0282 \\ http://lattes.cnpq.br/4983945900663400 \\ andreafaeufmg@gmail.com
}

\section{Resumo}

O presente estudo teve como objetivo analisar a circulação da "Moderna Ginástica Sueca" na Revista Brasileira de Educação Física, no período da sua existência, 1944-1952. A ginástica sueca, criada por Pehr Henrik Ling no início do século XIX, passou por uma reconfiguração na Europa dando forma a uma "Moderna Ginástica Sueca", que circulou no Brasil. A Revista Brasileira de Educação Física constituiu-se em um veículo no qual diferentes sujeitos que se dedicavam ao ensino da ginástica, apontavam uma forma de ginástica que contrapunha à rígida e monótona ginástica de Ling. Circula no Brasil, portanto, outra possibilidade de educar o corpo em um momento que a educação física brasileira debatia sobre a definição de um método adequado para o campo.

Palavras-chave: Educação Física. Moderna Ginástica Sueca. Revista Brasileira de Educação Física.

\footnotetext{
${ }^{1}$ Agência de fomento: FAPEMIG - Fundação de Amparo à Pesquisa do Estado de Minas Gerais.
} 


\begin{abstract}
The present study aimed to analyze the circulation of the "Modern Swedish Gymnastics" in the Brazilian Journal of Physical Education, during the period of its existence, 1944-1952. The swedish gymnastics, created by Pehr Henrik Ling in the early nineteenth century, underwent a reconfiguration in Europe constituting a "Modern Swedish Gymnastics", that circulated in Brazil. The Brazilian Journal of Physical Education it was an instrument of circulation in which different subjects dedicated to the teaching of gymnastics pointed to a form of gymnastics that opposed Ling's rigid and monotonous gymnastics. Therefore, in Brazil there is another possibility of to educate the body at a time when Brazilian physical education was debating the definition of a appropriate method for the field.
\end{abstract}

Keywords: Physical Education. Modern Swedish Gymnastics. Brazilian Journal of Physical Education.

\title{
Resumen
}

Este estudio tuvo como objetivo analizar la circulación de la "Moderna Gimnasia Sueca" en la Revista Brasileña de Educación Física, durante el período de su existencia, 1944-1952. La gimnasia sueca, creada por Pehr Henrik Ling a principios del siglo XIX, pasó por una reconfiguración en Europa para formar una "Moderna Gimnasia Sueca", que circuló en Brasil. La Revista Brasileña de Educación Física fue un vehículo en el que personas diferentes dedicadas a la enseñanza de la gimnasia señalaron una forma de gimnasia que se oponía a la gimnasia rígida y monótona de Ling. Circula en Brasil, por lo tanto, otra posibilidad de educar al cuerpo en un momento en que la educación física brasileña estaba debatiendo sobre la definición de un método adecuado para el campo.

Palabras clave: Educación Física. Moderna Gimnasia Sueca. Revista Brasileña de Educación Física. 


\section{Introdução}

O texto tem como propósito analisar a circulação da ginástica sueca, idealizada por Pier Henrik Ling, na Revista Brasileira de Educação Física (RBEF), no período de 1944 a 1952. Para tanto, se estrutura a partir da compreensão que a ginástica criada por Ling no início do século XIX, na Suécia, passou por adaptações e reconfigurações na sua longa existência, originando uma Moderna Ginástica Sueca que circula em diferentes periódicos no Brasil, dentre eles a RBEF.

Diferentes sistematizações da ginástica, as chamadas escolas, foram propostas na Europa, mais notadamente na Alemanha, Suécia e França (SOARES, 1994) e protagonizaram intensos debates em busca de definir uma ginástica mais eficiente/adequada e de base científica (SARREMEJANE, 2006). A ginástica sueca foi constituinte desse movimento ginástico europeu que emergiu desde fins do século XVIII, orientado por uma abordagem de corpo ancorada nos discursos científicos e higiênicos, que almejava adestrar os gestos e controlar as vontades ${ }^{2}$.

Seu idealizador, Pier Henrik Ling, nascido na Suécia em 1776, desenvolveu seu método de ginástica influenciado pelo contato que teve em Copenhagen, no período de 1799 a 1804, frequentando aulas no Instituto de ginástica de Nachtegall (1777-1847) ${ }^{3}$. Foi inspirado no trabalho dele ${ }^{4}$, que Ling retorna para Estocolmo e atua com esgrima na Universidade de Lund, por $8 \operatorname{anos}^{5}$. Nessa instituição ensina ginástica e se dedica, nesse período, aos estudos de anatomia e fisiologia que seriam centrais na constituição de sua principal obra, a Gymnastikens allmänna grunder $^{6}$ (WESTERBLAD, 1909; GEORGII, 1854; LEONARD, 1923; PEREIRA (S/d); MARINHO, 1958).

Em 1813 Ling começa a atuar como professor de esgrima na Academia Militar, em Karlberg, região norte da cidade de Estocolmo ${ }^{7}$. Ao mesmo tempo, propõe ao governo sueco a criação de um Instituto que seria responsável pelo treinamento físico para jovens, por meio da ginástica. Nasce, assim, o Instituto Central e Real de Ginástica (GCI ${ }^{8}$, em Estocolmo, sob a tutela da coroa sueca, que desenvolve e divulga o sistema lingiano, conhecido como a Ginástica Racional, em diferentes partes do mundo (GEORGII, 1854; LEONARD, 1923; WESTERBLAD, 1909; GRUT, 1913; HAGELIN, 1995).

Ling morre em 1839, mas sua obra continua e ganha repercussão em vários países, inclusive no Brasil. Aqui, desde fins do século XIX até meados do século XX, a circulação do Método Sueco de Ginástica acontece de variadas formas, dentre elas: brasileiros (intelectuais e políticos) que

\footnotetext{
${ }^{2}$ Diversos estudos já se debruçaram sobre esse tema, buscando compreender os métodos ginásticos. Entre eles podemos citar: Moreno (2001; 2003; 2015); Quitzau (2014; 2015, 2016); Soares (1994, 2009; 2015); Quitzau e Soares (2016); Jube (2017); Carvalho e Correia (2015); Góis Júnior (2015); Puchta (2015); Melo e Peres (2014); Goellner (1992); Andrieu (1999); Bui-Xuân e Gleyse (2001); Ljunggren (2011); Lundvall (2015); Rodríguez Giménez (2011); Sarremejane (2006); Scharagrodsky et al (2011).

${ }^{3}$ Segundo Pereira (s/d), Nachtegall já atuava na formação para atuar com a ginástica, seja na escola ou no exército.

${ }^{4}$ Outras relações de Ling em Copanhague, possivelmente, contribuíram com as escolhas e investimento de Ling. Leonard (1923) informa sobre o contato de Ling com diferentes sujeitos na sua passagem em Copenhague, tanto no âmbito da literatura - área de interesse e marcante na sua trajetória - quanto no seu investimento na ginástica e esgrima.

${ }^{5}$ Segundo Pereira (s/d), Ling se inspirou na ginástica de Guts-Muths, de Vieth e de Pestalozzi, na orientação filosófica de Schelling e na orientação pedagógica de Rousseau e Locke. Muito dessa inspiração se deve ao contato com Nachtegall, que se orientava por essas bases.

${ }^{6}$ Essa obra foi iniciada em 1834 e publicada após a morte de Ling, em 1840. Em português, essa obra tem sido traduzida como "Princípios gerais de ginástica", "Manual de ginástica" ou "Base geral para ginástica", conforme podemos observar em Moreno (2015).

${ }^{7}$ Segundo Leonard (1923), Ling continuou a ensinar esgrima na Escola Militar de Karlberg até 1825, sendo que em 1821 atuava também como instrutor em ginástica e esgrima na Escola de Artilharia em Marieberg.

${ }^{8}$ Tradução de Stockholm Central Institute of Gymnastics (GCI). Durante um tempo, o instituto tinha o nome de Royal Gymnastics Central Institute. Ao longo do texto, nos referimos ao Instituto usando a sigla GCI, como é mundialmente conhecido.
} 
tomavam conhecimento do sistema e o divulgavam de diferentes formas e em diferentes espaços ${ }^{9}$; suecos que aqui aportam para atuar com a ginástica ${ }^{10}$; obras traduzidas que chegam ao país ${ }^{11}$; obra produzida no Brasil inspirada no método sueco ${ }^{12}$; além de jornais, revistas e periódicos especializados da Educação Física que colocavam em circulação a ginástica sueca ${ }^{13}$.

O campo da Educação Física foi se consolidando com a contribuição de um conjunto de periódicos especializados que emergiram a partir da década de 1930, sendo eles: Revista Educação Física (1932-1960), Revista Educação Physica (1932-1945), Boletim de Educação Física (1941-1958), Revista Brasileira de Educação Física (1944-1952) e Arquivos da Escola Nacional de Educação Física e Desportos (1945-1966) (FERREIRA NETO, 2005). Para o autor, a RBEF se constituiu em um lugar privilegiado, onde conhecimentos diversos acerca das práticas corporais, inclusive a ginástica sueca, circularam, instigaram o debate, encontraram resistências, moldaram formas de ser e pensar a educação do corpo por meio das práticas corporais, contribuindo com a constituição da Educação Física nesse período ${ }^{14}$.

Como tema de pesquisa, os periódicos no Brasil têm sido largamente interrogados. Entretanto, se os periódicos já têm sido problematizados no âmbito das pesquisas em História da Educação e da Educação Física ${ }^{15}$, não se pode relatar o mesmo em relação à ginástica sueca ${ }^{16}$, nem tampouco em estudos que tomam como fonte a $\mathrm{RBEF}^{17}$. Como se deu o processo de organização da ginástica sueca, entre início do século XIX e meados do século XX, na Europa, que possibilitou o surgimento da Moderna Ginástica Sueca? Como essa Moderna Ginástica Sueca aparece na RBEF e contribuiu com a configuração do campo da Educação Física?

Orientados por essas questões, propomos nesse estudo compreender como a Moderna Ginástica Sueca foi difundida no Brasil por meio da Revista Brasileira de Educação Física, contribuindo com um debate sobre a constituição da Educação Física no período de 1944-1952 ${ }^{18}$.

Para tanto, utilizamos os 82 números da RBEF, representando a totalidade do periódico publicado no período de 1944 a 1952. Inspirados em Certeau (2006, p.81), para quem em história tudo começa com o gesto de separar, reunir e transformar em documentos certos objetos distribuídos

\footnotetext{
${ }^{9}$ Rui Barbosa defende a ginástica sueca em seu parecer (1947); Fernando de Azevedo (1920), Inezil Penna Marinho (1958) e Jair Jordão Ramos (1952,1982) em seus escritos.

${ }^{10} \mathrm{O}$ estudo de Moreno e Baia (2019) apontam a presença dos suecos Fritjof Detthow, Mme. Will, Mme. Ester Leo, SvenKellander, Artur Linderdahl, Mme. Maria Grushka e Curt Johansson, que de alguma forma tiveram sua atuação relacionada à ginástica sueca, seja ministrando cursos, seja escrevendo em jornais e atuando em escola, seja atuando com a dimensão médica da ginástica sueca.

${ }^{11}$ Baía, Bonifácio e Moreno (2017a).

12 Avelar (2018)

${ }^{13}$ Para citar alguns jornais: Folha da Manhã (SP), Jornal do Commercio (RJ), Jornal do Recife, O Commercio de São Paulo, O Estado de São Paulo, Revista Educação (São Paulo). No que se refere aos periódicos especializados, citamos: Revista Educação Physica (1932-1945), Revista de Educação Física (1932-atual) e a RBEF (1944-1952).

${ }^{14}$ A definição da RBEF como fonte privilegiada desse estudo se ancorou no número de reportagens sobre ginástica sueca levantadas em uma análise prévia. Superava, em muito, o quantitativo de reportagens sobre ginástica sueca nos demais periódicos especializados, o que nos chamou atenção. Porque a RBEF, dentre os periódicos especializados, se constituiu em principal veículo de circulação da ginástica sueca no país.

${ }^{15}$ No campo da História da Educação Física, podemos citar: Góis Júnior e Mattos (2016); Moraes e Góis Júnior (2015); Góis Júnior (2013); Bruschi e Schneider (2019); Assunção et al (2014); Ferreira Neto et al (2014); Schneider et al (2013); Schneider (2004); Berto, Schneider e Ferreira Neto (2007); Moraes e Fontoura (2011). Há outras pesquisas que poderiam entrar nesse rol - tarefa que exigiria mais cuidado e um estudo específico para tal. Essa tarefa foge aos objetivos desse texto.

${ }^{16}$ Para citar alguns: Moreno (2001, 2015); Soares e Moreno (2015); Romão e Moreno (2018); Baía, Bonifácio e Moreno (2017a; 2017b); e Avelar (2018).

${ }^{17} \mathrm{O}$ trabalho de Moraes e Fontoura (2011) é um dos raros estudos que tomam a RBEF como fonte principal. Outros estudos, como os de Retz et al (2019), Ferreira Neto et al (2014), Cassani (2018), tomam-a no conjunto de outros periódicos. Mesmo considerando esses últimos estudos, ainda são poucos os que se dedicam a análise desse periódico, que contribuiu significativamente com a circulação de conhecimentos sobre o campo da Educação Física.

${ }^{18}$ A delimitação do período de estudo coincide com o tempo de vida do periódico. Mais informações sobre ele serão trazidas no transcorrer do texto.
} 
de outra maneira, acessamos os exemplares da RBEF na Biblioteca da Faculdade de Educação da Universidade de Campinas e no Instituto de Educação e Educação Física - PROTEORIA - situado no Centro de Educação Física e Desportos da Universidade Federal do Espírito Santo.

O corpus documental foi constituído pelas reportagens da RBEF que abordavam a Ginástica Sueca e/ou a Moderna Ginástica Sueca ${ }^{19}$. A exploração das fontes nos permitiu perceber que essa Moderna Ginástica Sueca circulou com intensidade nesse periódico no período analisado, tornando possível, com o cotejo com a literatura, compreendê-la como parte de um movimento de reconfiguração que passa a Ginástica Sueca na Europa, circulando por diferentes lugares, dentre eles, o Brasil.

\section{Da ginástica de Ling à Moderna Ginástica Sueca}

A ginástica sueca criada por Ling no início do século XIX passou por transformações ao longo de sua trajetória. No Instituto criado com a contribuição dele, no qual foi diretor de 1813 a 1839, assumiu o trabalho sozinho até 1818, momento que recebe o médico Gabriel Branting, que havia sido seu aluno na primeira turma no GCI e seu auxiliar na Academia Militar de Karlberg ${ }^{20}$ (PEREIRA, S/d; LEONARD, 1923)

Em 1929 o Instituto recebe Carl August Georgii ${ }^{21}$, que juntamente com P. J. Liedbeck ${ }^{22}$ foram responsáveis pela finalização da já citada obra de Ling, intitulada Gymnastikens allmänna grunder $^{23}$, a qual organiza as experiências de Ling na sua trajetória com a ginástica sueca.

Soma-se a esse trabalho no Instituto, o filho do idealizador, Hjälmar Fredrik Ling, em 1843. Sua contribuição na sistematização da obra do pai, agrupando os movimentos em "esquema", "Lição", foi fundamental no alcance da ginástica sueca em diferentes regiões do mundo (LANGLADE e LANGLADE, 1970; PEREIRA, S/D) ${ }^{24}$.

Esses três sujeitos - Branting, Georgii e Hjälmar - mais do que reproduzir os conhecimentos do idealizador, atuaram no aperfeiçoamento do seu método. A tarefa dos seguidores não foi tranquila - Ling não deixou muitos escritos sobre a ginástica de forma a auxiliar a continuação de seu trabalho (LINDROTH, 1979). A forte marca filosófica em sua principal obra, supracitada, dificulta sua compreensão. Com isso, muito do que se atribui a Ling tem a mediação e a marca das experiências que Branting e Georgii estabeleceram com o precursor, resultado do convívio de décadas.

19 No início da pesquisa, acessamos os títulos das reportagens de alguns dos principais periódicos especializados que emergiram a partir da década de 1930, sendo eles: Revista Educação Física (1932 -1960), Revista Educação Physica (1932-1945) e Revista Brasileira de Educação Física (1944-1952), por meio do Catálogo de periódicos de Educação Física e esporte (Ferreira Neto, Schneider, Aroeira, Bosi, Santos, 2002). Nesse momento, identificamos que a Revista Brasileira de Educação Física possibilitou uma circulação intensa de reportagens sobre ginástica sueca, sendo, quantitativamente, muito superior às reportagens sobre esse tema nos outros periódicos, sendo, portanto, o principal critério de seleção da Revista Brasileira de Educação Física para esse estudo.

${ }^{20}$ Atuou na Academia Militar de Karlberg entre os anos de 1813 e 1825 (LEONARD, 1923).

${ }^{21}$ Nascido em 1808, foi um dos discípulos de Ling. Divulgou a obra de Ling Na França e na Inglaterra, falecendo em 1881 (PEREIRA, S/D).

${ }^{22}$ Nascido em 1802, foi genro de Ling e atou com ensino de Anatomia no Instituto de Ginástica de Estocolmo. Faleceu em 1876 (PEREIRA, S/D).

${ }^{23}$ Apresenta a seguinte divisão: 1) As Leis do Organismo Humano; 2) Ginástica Pedagógica. Fundamentos; 3) Ginástica Militar. Fundamentos; 4) Ginástica Médica. Fundamentos; 5) Ginástica Estética. Fundamentos; 6) Os Veículos da Ginástica. Contudo, durante o período de atividade de Ling, foi a ginástica médica que mais atraiu sua atenção (PEREIRA, S/D).

${ }^{24}$ Esquema, para Hjälmar Ling era definido como a relação das famílias, grupos e subgrupos de exercícios, segundo a ordem que se deve empregar, para o correto desenvolvimento de uma lição, contemplando a exigência de atividade completa e um ajuste aos princípios da continuidade, progressão, variedade e alternância (LANGLADE e LANGLADE, 1970, p. 370) 
Ling, pouco antes de sua morte, afirmava que confiava em Branting e Georgii na continuação de sua obra, o que possivelmente se construiu com os anos de convivência no trabalho diário no Instituto (PEREIRA, S/D). Portanto, analisando esse primeiro momento da ginástica sueca, representado pela atuação desses sujeitos, havia certo alinhamento no preparo para atuar com o ensino da ginástica sueca ${ }^{25}$ e no desenvolvimento do método de Ling, seguindo os princípios de seu idealizador. Com o propósito de ampliar a compreensão dos responsáveis pela continuação do trabalho iniciado por Ling, apoiamo-nos na subdivisão da ginástica sueca apresentada por Langlade e Langlade (1970):

Figuras 1 e 2 - Organização da Ginástica Sueca segundo Langlade e Langlade (1970)
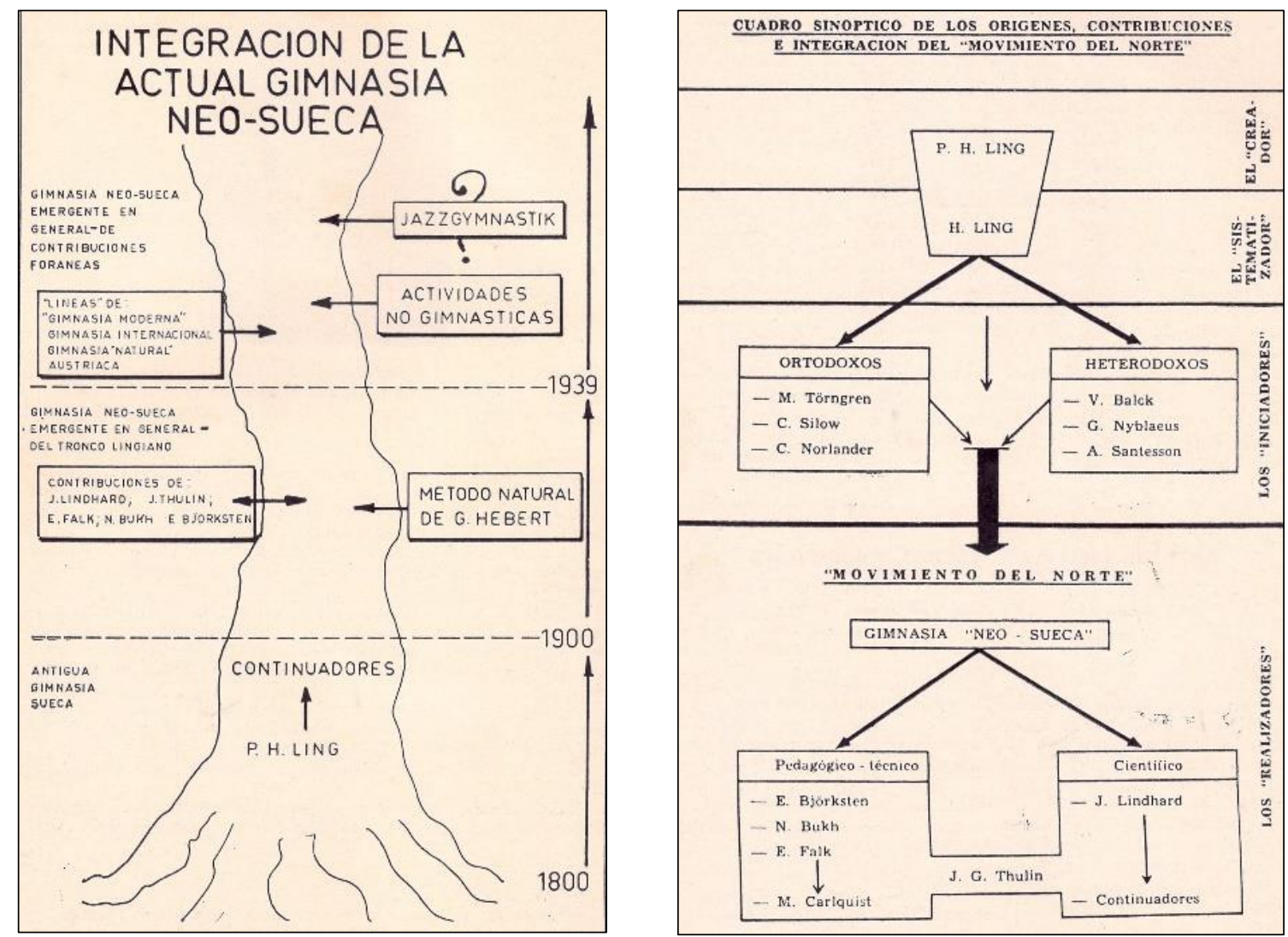

Fonte: Langlade e Langlade (1970, p. 368 e 163)

Entre os anos de 1800 a 1900, P. H. Ling e seus continuadores constituem uma ginástica classificada como "Antiga Ginástica Sueca". Contribuíram, nesse período, dois grupos: os ortodoxos, alinhados a Branting, Georgii e Hjälmar, que buscavam manter a base de Ling como princípios que guiavam a formação e desenvolvimento do método; e os heterodoxos, que sustentados por justificativa semelhante, propunham o desenvolvimento do método a partir de influências diversas.

Compondo os ortodoxos, estavam: Lars Mauritz Törngren, sucessor de Hjälmar Ling no trabalho com a ginástica pedagógica no Instituto, atuando com ela de 1883 a 1909, sendo também diretor no período de 1887-1907; Carl Silow, que atuou contribuindo com Törngren

\footnotetext{
${ }^{25}$ Segundo Pereira (s/d), havia três formações diferentes, ofertada em três anos: em um primeiro ano, formava instrutores, preparando para atuar no exército e nos graus elementares do ensino escolar. O segundo ano constituía o curso de formação de professores, preparando para atuar nos Liceus. O terceiro ano representava o curso de ginástica médica, habilitando ao grau de diretor de ginástica, ou como afirma Posse (1891), médico-ginásta. O aluno faria um, dois ou três anos, dependendo da formação almejada. Os conhecimentos que faziam parte dessas formações podem ser consultados em Moreno e Baía (2019).
} 
na ginástica pedagógica de 1883 a 1909; e Carl Anders Henrik Norlander, que foi professor da Universidade e Escola Normal em Lund e em muito contribuiu com a ginástica pedagógica, especialmente a partir de suas obras escritas sobre o assunto ${ }^{26}$.

Entre os heterodoxos, estavam: Viktor Gustav Balck, que atuou com a ginástica militar de 1883 a 1909, sendo ainda diretor do GCI de 1907 a 1909; Gustav Nyblaeus, aluno de P. H. Ling, foi diretor de 1862 a 1887 e atuou com ginástica militar de 1838 a 1887 e foi incentivador do movimento desportivo na Suécia, considerando essa modalidade como essencial e complementar à ginastica; e Anton B. Santesson, que juntamente com Nyblaeus, foram os primeiros críticos da ginástica organizada por Hjälmar Ling, afirmando que está se distanciava das ideias do fundador do método de ginástica sueca ${ }^{27}$.

É possível inferir que essas disputas que marcaram o período final do século XIX ortodoxos $\mathrm{x}$ hetorodoxos - representavam mais do que uma defesa de formas de desenvolvimento da ginástica sueca de Ling. Significava, também, disputa de poder e busca de hegemonia na constituição da ginástica. O final do século XIX e início do século XX na Europa caracterizam-se como tempo e lugar onde emergem diferentes propostas para a educação do corpo, com diversas propostas de métodos ginásticos (SARREMEJANE, 2006).

Se considerarmos os envolvidos com a ginástica sueca no final do século XIX em comparação com os da primeira metade do século XIX, cresce, consideravelmente, o número de sujeitos que se dedicam a formação e desenvolvimento dessa ginástica. Aquela ginástica sueca "matricial", caracterizada pela presença efetiva de P. H. Ling na sua organização e desenvolvimento, continuada por pessoas que com ele conviveram e a defendiam, como Branting, Georgii e Hjälmar Ling, começou a se reorganizar no final do século XIX ${ }^{28}$, dando origem a um movimento renovador. Esse movimento renovador da ginástica sueca, iniciado após 1900, Langlade e Langlade (1970) intitula de "Ginástica neo-sueca".

A ginástica "neo-sueca" apresenta como característica central as contribuições de diferentes sujeitos, que partem de uma formação comum na ginástica Lingiana, muitos deles formados no próprio GCI. O que temos de diferente é que para além da formação em ginástica sueca sustentada pela base de Ling, os renovadores se valiam de influências externas, advindos das inovações científicas que sustentavam os métodos ginásticos e das diversas correntes ginásticas que emergem no final do século XIX e início do século XX, a exemplo do método natural de George Hébert, indicado por Langlade e Langlade (1970) como um dos influenciadores. São personagens centrais desse movimento de renovação da ginástica sueca: Elin Falk, Elli Björksten, Maja Carlquist, Niels Bukh, Johannes Lindhard e Josef Gittfrid Thulin (LANGLADE e LANGLADE, 1970; PEREIRA, S/D).

Até final dos anos 30 do século XX, todos esses sujeitos que contribuíram no campo técnico-pedagógico e científico, a partir de suas experiências e intervenções, dialogaram a partir da corrente linguiana de ginástica sueca, dando origem a esta nova expressão ginástica, a "neosueca". Para Holmströn, Secretário-geral da Federação Sueca de Ginástica, organizador das Lingíadas de 1939 e $1949^{29}$, essa ginástica assinalada como "neo-sueca” por Langlade e

${ }^{26}$ Cf: Pereira (s/d, p. 435).

${ }^{27}$ Sobre Nyblaeus, cf: Pereira (s/d, p. 403).

${ }^{28}$ Lindroth (1979) afirma que o GCI foi reorganizado em 1864, quando um novo conjunto de estatutos foi emitido. Essa reorganização promoveu uma divisão da formação em ginástica sueca em três pequenos departamentos - ginástica pedagógica, militar e médica - cada um dirigido por um professor-chefe. Através da nova organização demarcações entre os principais sectores da ginástica de Ling tornou-se ainda mais clara. Ao mesmo tempo em que essa organização poderia contribuir para um melhor equilíbrio de interesses e recursos, também tendia a estimular a rivalidade entre os respectivos departamentos.

${ }^{29}$ A Lingíada foi um evento internacional de demonstração e debate das práticas culturais representativas da Educação Física de diferentes países. Abordaremos com maiores detalhes ao longo do trabalho. 
Langlade (1970), era denominada de "Moderna Ginástica Sueca"30. Em seu livro intitulado $A$ Moderna Ginástica Sueca, esses sujeitos reaparecem como peças fundamentais no processo de desenvolvimento da ginástica sueca:

La gimnasia há modificado también sus métodos de trabajo. Esto es muy certo, especialmente en lo que se refiere a la gimnasia pedagógica escolar y a la gimnasia voluntaria. Bajo la influencia de pedagogos prominentes adictos a la gimnasia de Ling en los distinos países escandinavos - Elin Falk y el comandante J. G. Thulin en Suecia, Elli Björkstén en Finlandia y Niels Bukh en Dinamarca - se han modificado, desarrollado y enriquecido las formas de trabajo gimnásticas, em tal grado que ahora es posible variar la gimnasia según el sexo, la edad y las condiciones físicas de los gimnastas. La gimnasia infantil, la gimnasia para mujeres y la gimnasia para hombres se han desarrollado de distinta manera, adaptándose a las distintas tareas educativas que ahora se quieren llevar a cabo mediante distintas formas de gimnasia, así como de los métodos de trabajo gimnásticos. (HOLMSTRÖN, 1949, p. 42-43)

Os investimentos desses sujeitos tomaram como base a "Antiga Ginástica Sueca" e representou um rompimento com a ortodoxia e espírito fechado da ginástica de Ling. O auge desse Moderna Ginástica Sueca é marcado pela I Lingíada, em 1939 (LANGLADE e LANGLADE, 1970, p. 249).

No período pós-1939, dois eventos são marcantes: a primeira e a segunda Lingíadas, respectivamente nos anos de 1939 e 1949. Segundo Langlade e Langlade (1970), a primeira constituiu-se em oportunidade mundial de ampliação de conhecimento e difusão das escolas, sistemas, métodos ou linhas de trabalho, iniciando uma época de influências recíprocas e universalização das concepções ginásticas. A segunda Lingíada representa a demonstração objetiva das influências recíprocas das escolas, sistemas, métodos ou linhas de ginástica.

Para Langlade e Langlade (1970), o velho tronco lingiano que durante mais de 130 anos exerceu influências em toda manifestação mundial de ginástica, exportando teoria, técnicas e procedimentos metodológicos, se converteu a partir da década de 1940 em uma ginástica mais aberta a recepção de influências externas. Essas influências vêm da "ginástica moderna"31, da "ginástica internacional", da "ginástica natural austríaca" e da "ginástica jazz" e encontraram nas Lingíadas, especialmente na segunda, um espaço de troca ${ }^{32}$.

${ }^{30}$ Estamos assumindo no trabalho a denominação Moderna Ginástica Sueca por ser assim referida nas reportagens presentes na RBEF.

${ }^{31}$ Ao referirmos à "ginástica moderna" a partir de Langlade e Langlade (1970), entende-se esta originária na Alemanha, caracterizando um movimento, a princípio voltado à ginástica feminina, inspirada no campo do teatro, da música e da dança. A ginástica internacional, natural austríaca e jazz também são encontradas na referida obra.

32 Para Langlade e Langlade (1970), dentre essas influências, advindas das diferentes vertentes ginásticas, destaca-se: a) A organização da aula de ginástica sueca sob o forma de "esquema" e "lição" se manteve até 1939, quando passou a ser possível montar uma seção de ginástica sueca a partir do trabalho de um tema ou trabalho em circuito; b) $\mathrm{O}$ uso de diferentes aparatos manuais, com predominância das cordas, bolas de diferentes tamanhos, aros e tamborins; c) O uso de música no comando, de preferência, mas aberto ao acompanhamento através de músicas gravadas; d) Organização dos exercícios no espaço, abandonando a ideia da ginástica "no lugar", orientando o deslocamento dos executantes na superfície disponível de trabalho; e) Criação de movimentos, que se concentrou mais efetivamente com as crianças, abandonando a ideia de uma ginástica imagino-imitativa para a imaginação-criadora; f) Possibilidade de organização da seção de ginástica em estações que utilizavam materiais diversos, criando um rodízio, na quais os grupos se deslocam com determinada frequência; g) Abertura de espaço para o jogo individual, livre, espontâneo das crianças, reduzindo a rigidez e direcionamento exclusivo do professor no direcionamento em toda a seção. 
Para Agne Holmström, a ginástica sueca do final do século XIX estava petrificada, especialmente devido a influência excessivamente militar. No lugar de alegria, animação e originalidade que deve constituir a "verdadeira ginástica", nos anos de 1900 verificava-se uma ginástica de posições estereotipadas, que suprimiu a alegria, contribuindo com a caracterização dela como "a triste ginástica sueca" (RBEF, no 46, jan. de 1948, p. 39-43). Esse foi ponto central que levou a modificar a forma de pensar e praticar a ginástica sueca.

As diferentes influências pelas quais passaram a ginástica de Ling desde sua criação se intensificaram nos primeiros anos do século XX, moldando uma Moderna Ginástica Sueca. Esta nova ginástica, circulou. A RBEF foi um veículo que contribuiu com a circulação da Moderna Ginástica Sueca, tendo a segunda Lingíada um espaço de grande relevância no periódico ${ }^{33}$.

\section{A Moderna Ginástica Sueca na Revista Brasileira de Educação Física}

Na historiografia brasileira, intelectuais incentivaram a ginástica sueca na formação dos corpos na escola. Desde os pareceres de Rui Barbosa, em 1882, a ginástica sueca era indicada para a formação dos alunos nesse espaço (MARINHO, S/D). Ainda no século XIX, quando a Moderna Ginástica Sueca ainda não estava em voga, Rui Barbosa defendia nas escolas brasileiras a "Antiga Ginástica Sueca".

Fernando de Azevedo foi outro intelectual brasileiro a defender a presença da ginástica sueca na formação dos escolares no país:

Este método, incontestavelmente o melhor do ponto de vista pedagógico, é chamado a suprir no sistema de educação uma grave lacuna que antes do século XIX os governos e particulares deixavam em aberto e que ainda alguns países não se preencheu por imperdoável incúria a preconceitos já em demasia radicados. (AZEVEDO, 1920, p. 118)

Critica o tipo de método sueco que se efetiva em grande número das escolas do país, ressaltando que "não são mais do que um gênero mais ou menos feliz de ginástica sueca, isto é, uma aplicação mais ou menos direta do método de Ling" (AZEVEDO, 1920, p. 119) ${ }^{34}$. Defende a ginástica educativa de matriz Lingiana, difundida por Lefebure ${ }^{35}$, método "moldado sobre os princípios racionais estabelecido pelo genial sueco" (AZEVEDO, 1920, p. 119). A defesa da ginástica pedagógica já nos indica o vínculo de Fernando de Azevedo com o momento de atuação de Hjälmar Ling, responsável por desenvolver essa dimensão marcante do método sueco em meados do século XIX. Essa dimensão pedagógica do método encontrou defensores e divulgadores não apenas em Lefebure, mas nos Franceses Lagrange, Tissié e Coste, apontados pelo brasileiro em sua obra como conhecedores dos princípios que regem o método sueco e a partir dos quais apresentar as características do método sueco: não necessidade de aparelhos, ênfase na respiração, entre outras. Através da escolha de Fernando de Azevedo pela ginástica pedagógica, desenvolvida

\footnotetext{
${ }^{33}$ Encontramos 43 reportagens que tematizavam diretamente a Ginástica Sueca na Revista Brasileira de Educação Física, no período de sua existência. Destas, 22 reportagens tratavam das Lingíadas.

34 Quitzau, Moreno e Baía (2019), instiga a ter cautela ao tratarmos dos métodos ginásticos. Os diferentes métodos - Alemão, Sueco, Francês, etc, escritos pelos diferentes autores, ainda que compartam exercícios e algumas finalidades, cada um destes autores se debruçou sobre o estudo do gesto humano a partir de uma perspectiva diferente, e isso, em diferentes níveis, se reflete em seus escritos e suas ideias, nas formas como selecionam o que seria ou não apropriado a seus métodos. Portanto, provavelmente os continuadores do método de Ling fizeram outra coisa daquela célula matricial. Diferentes métodos suecos foram sendo reconfigurados e circularam por diferentes regiões do mundo, inclusive no Brasil.

${ }^{35}$ Nascido em 1861, foi membro do exército Belga, enviado à Suécia para estudar o método de Ling no final do século XIX. Foi um dos importantes propagandistas da ginástica sueca. Faleceu em 1928. (PEREIRA, S/D)
} 
por Hjälmar Ling, e pela sustentação em defensores da ginástica sueca marcantes do final do século XIX, podemos suspeitar que Fernando de Azevedo, em 1920, não estava impactado pela reconfiguração da ginástica sueca que estava em curso desde os últimos anos do século XIX, capitaneadas por Elin Falk, Elli Björksten, Maja Carlquist, Niels Bukh, entre outros.

Mas já havia em Azevedo abertura à recepção de uma ideia de reconfiguração do método, quando afirma que "não seria racional rejeitar os recursos com que as experimentações da fisiologia poderiam melhorar a ginástica de Ling". Posiciona-se a favor das reformas no método de Ling, "para sua adaptação cada vez mais perfeita ao fim a que admiravelmente se destina como ginástica fisiológica educativa" (AZEVEDO, 1920, p. 124).

Essa adaptação, inclusive, aparece em reportagens na RBEF e é recorrentemente colocada, especialmente por defensores da Moderna Ginástica Sueca, especialmente Agne Holmström, como desejo de Ling. O fundamento desse argumento é retirado da apresentação do livro base da ginástica de Ling, intitulado Gymnastikens allmänna grunder, no qual o sueco afirma que: "Espero que os futuros Médicos e Educadores deem continuidade a este trabalho ampliando e aprofundando as noções aqui contidas" (LING, 1834-1840, s/p.). O discurso da adaptabilidade vai permitir moldar outra ginástica, A moderna Ginástica Sueca, pensada para novos tempos, novos espaços, com nova organização didática.

Já em Inezil Penna Marinho, no início da década de 1950, a ginástica sueca aparece dividida em "Antiga Ginástica Sueca", marcada pelos trabalhos de Ling e seus continuadores do século XIX, e "Moderna Ginástica Sueca", marcada pela presença de figuras centrais na sua reconfiguração, como Elin Falk, Elli Björksten Niels Bukh, Johannes Lindhard e Major Thulin.

Na década de 1950 Inezil já havia tido contato com a Moderna Ginástica Sueca por diversas vezes na RBEF. A primeira reportagem tematizando ginástica sueca na RBEF é intitulada $O$ Sistema Suéco Baseado na Ginástica de Ling, Adaptado ao Sexo Feminino, na Argentina, de autoria de Magdalena E. B. de Mayne, representante do Instituto Nacional de Educação Física da Argentina, e traduzida por Eunice Galvão Antunes ${ }^{36}$. A reportagem está na edição número 02, em fevereiro de 1944 e nas suas primeiras palavras, percebe-se a adaptabilidade do método de Ling: "Um dos princípios básicos da ginástica estabelece que a mesma deve ser adaptada à idade, desenvolvimento e sexo do aluno". Segundo a autora, "ninguém pretenderá implantar hoje em dia o sistema que Ling idealizou em sua forma original, justamente porque êsse sistema foi idealizado em outra época e para outra gente" (RBEF, nº 02 , fev. de 1944, p. 39).

Esse investimento de adaptar o método de Ling ao sexo e idade estava no horizonte dos continuadores de Ling desde a segunda metade do século XIX. Segundo Pereira (s/d), Hjälmar Ling interessou pela ginástica feminina em 1860, tendo sua irmã, Wendla Dahl Ling publicado em 1878, um trabalho destinado às instrutoras. Contudo, a continuação e maior investimento nesse movimento de pensar a ginástica feminina e a adaptação à idade, segundo Langlade e Langlade (1970), tiveram a contribuição e protagonismo das professoras Elli Björksten e Elin Falk, já na transição do século XIX para o século XX, estendendo-se para as primeiras décadas deste. Elli Björksten, por exemplo, terminou seus estudos no Instituto no final do século XIX:

Durante mis estudios en el Instituto Central de Gimnasia de Estocolmo - 1893 a 1895 o encontré que los principios sobre los cuales P. H. Ling trazó sus ideas relacionadas con la educación física, eran geniales y de indiscutible valor. Pero vi igualmente que el sistema desarrollado por sus continuadores dejaba mucho que desear desde el punto de vista pedagógico, al menos en lo que se relacionaba con la mujer y con el

\footnotetext{
${ }^{36}$ Eunice Galvão Antunes, em 1943, foi removida do cargo de datilógrafa lotada na Direção Nacional da Juventude Brasileira para a Divisão de Educação Física (Diário Carioca, edição 4685, ano 1943, p.3). Não encontramos o cargo e função que desempenhava nesse órgão. A Divisão de Educação Física primeiro órgão governamental federal a organizar especificamente as ações e diretivas referentes à Educação Física (CUNHA, 2017).
} 
niño. Los sucessores de Ling, a mi juicio, mataban el espíritu del creador de la gimnasia moderna y aprisionaban su sistema en um marco demasiado estrecho y en formas que de ninguna manera nos atrevemos a pensar, hubieran satisfecho al gênio y alma fogosa de Pedro Enrique Ling. (LANGLADE e LANGLADE, 1970, p. 170)

Os investimentos inaugurais dos irmãos Hjälmar Ling e Wendla Dahl Ling não teriam sido suficientes na organização de uma ginástica adaptada ao sexo e a idade. Assim, Falk trabalhou na organização de uma ginástica infantil e Björksten inseriu o ritmo como parte característica da ginástica feminina. Essa atuação esteve estampada na RBEF:

A excelente pedagoga sueca de Educação Física, Elin Falk, introduziu impulsos vivificantes e novos para a reforma da ginástica infantil, criando desta forma uma nova era do desenvolvimento da ginástica de Ling. Pouco tempo depois, a finlandesa Elly Björkstén, que havia cursado o Instituto Central de Ginástica, fundado por Ling, empenhou em dar forma a uma ginástica especial para mulheres de acordo com os princípios de Ling, no que diz respeito especialmente a importância do ritmo para a ginástica. (RBEF, nº 46, Jan. de 1948, p. 42.)

Os escritos de Elin Falk e Elly Björkstén não são encontrados nas páginas da RBEF. Suas contribuições aparecem indiretamente em algumas reportagens, ressaltando seu protagonismo no desenvolvimento da ginástica sueca, como no texto de Agne Holmström, La Gimnasia de Ling como base racional de la moderna Educacion Física (RBEF, $\mathrm{n}^{\circ} 46$, jan. de 1948; RBEF, $\mathrm{n}^{\circ}$ 61/62, mai. De 1949). Nesse texto, soma-se a essas duas personagens, o Major Josef Gottfrid Thulin.

No Brasil, os trabalhos de Thulin circulam na RBEF em 3 reportagens na década de 1950, nos números 74, 75/76 e 77/78 37 , todas com o título de $O$ Esquema da Lição de Ginástica. Diferentemente do que pode dar a ver o título, que sugere uma organização prática, um esquema de uma lição, nota-se uma narrativa carregada de explicações baseadas na fisiologia, na anatomia:

Se o trabalho muscular for acompanhado de um aumento de volume do sangue expelido pelo coração em cada minuto, e se, no mesmo tempo, a resistência, a vencer pela pressão sanguínea, se mantiver sem alteração, a atividade muscular representará, sem dúvida, uma sobrecarga para o coração. Esta sobrecarga varia em função do esforço e do trabalho muscular. Pode, igualmente, variar com as diferentes formas de trabalho. (RBEF, $n^{\circ} 75 / 76$, jun/jul de 1950, p. 4-5)

As três reportagens recorrem constantemente a sustentação em conhecimentos "científicos", ressaltando essa característica do Thulin no trabalho com a ginástica sueca: "segundo o professor de Ortopedia, J. Haglund"; baseado no "fisiologista da ginástica, Prof. Lindhard"; ao propor o repouso como essencial ao desenvolvimento entre uma sessão e outra, ancora-se em "E. Asmussen" e "E. Hansen". O conhecimento científico é base de seu esquema da lição de ginástica que não se traduz em um conjunto de exercícios descritos para serem seguidos.

Para Thulin, a lição representa os ensinamentos necessários a serem trabalhados em um período de tempo, que usualmente ocupa de 40-45 minutos. Na Suécia agrupam esses ensinamentos sob a denominação de "Esquema da Lição de Ginástica", e "quando falamos na Ginástica sueca de

\footnotetext{
${ }^{37}$ Dessas três reportagens, encontrei apenas a referente ao número 75/76, que indicava ser continuidade da $\mathrm{n}^{\circ}$ 74 , e que continuaria no $\mathrm{n}^{\mathrm{o}} 77 / 78$.
} 
Ling, no seu emprêgo e distribuição, pensamos na maneira de organizar o esquema com exercícios, simultaneamente, construídos e funcionais" (RBEF, n 74, mai. De 1950, p. 8).

Com essa base de pensamento, ele defende a organização de um esquema de lição segundo a característica do público:

A lição diária de Ginástica deve variar de composição, conforme se trate de pessoas que levem uma vida de trabalho intenso, ou uma vida sedentária, quer intelectual, quer burocrática. Assim, a lição diária de Ginástica terá de ser diferente, quando se trate de pessoas que têm de realizar um intenso trabalho mental após a lição, ou de pessoas que, depois dela, nada tenham a fazer. (RBEF, $\mathrm{n}^{\circ}$ 77/78, ago/set. 1950, p. 5)

Essa forma de Thulin apresentar a ginástica sueca e os conhecimentos sobre a forma de ensino, pressupõe uma autonomia ao professor, necessitando de conhecimento específico e pedagógico da ginástica sueca. Sua contribuição na RBEF, nas três reportagens seqüenciais, não são indicações de um grupo de exercícios, apesar de apresentar a estrutura de um esquema de lição: inicia-se com uma introdução, onde "adotar-se-ão exercícios animados e jogos". Em seguida, "aparece a parte mais importante do esquema da lição, que se divide em: Parte Formativa $^{38}$ e Parte Aplicada (Parte Prática). Após essas, a Conclusão, no caso de se tornar necessária". Thulin afirma que "cada professor poderá elaborar, por si próprio, um esquema, tendo em considerações os diferentes aspectos" (RBEF, no77/78, ago/set. de 1950, p. 5).

Diferente do caminho construído por Thulin para o ensino da ginástica sueca, no qual apresenta um esquema de lição a partir de questões que devem ser levadas em consideração para montar uma aula de ginástica, podemos encontrar na RBEF outros autores que propõem modelos delineados, detalhados, prontos para serem utilizados em aulas.

Duas reportagens de Curt Johansson são encontradas em dezembro de 1949. Johansson, Sueco, foi personagem importante no desenvolvimento da Moderna Ginástica Sueca. Teve participação na segunda Lingíada, em 1949. Recebeu a delegação brasileira que foi ao evento, como representante do Instituto Real Central de Ginástica de Estocolmo. Pouco tempo depois, foi convidado a ministrar curso de Educação Física no Brasil a cerca de 300 professores de estabelecimentos secundários. Em 1951, em Santos, atua no Curso Internacional de Educação Física, promovido pelo Departamento de Educação Física e Esportes do Estado de São Paulo (PUBLIO e CATALANO, 2006). Aproveitou a vinda e esteve na Escola de Educação Física da Universidade do Brasil, no Rio de Janeiro, ministrando curso para professores e alunos. Além dessas trocas, passou a serem recorrentes em periódicos brasileiros os escritos de Curt Johansson, divulgando a ginástica sueca moderna, como podemos perceber na RBEF, poucos meses após a Lingíada, e em diversos jornais do período (MORENO e BAÍA, 2019).

As reportagens de Curt Johansson na RBEF caracterizam-se como roteiros, organizado para serem utilizados por professores de ginástica na sua intervenção. A primeira, intitulada Ginástica para homens: lições de ginástica sueca, fez parte de um curso de formação de professores na Suécia:

As três lições que compõem o presente trabalho foram ministradas pelo prof. Curt Johansson, no Curso Internacional de Ginástica, organizado pelo Real Central Instituto de Estocolmo e traduzem as mais modernas características da ginástica sueca. (RBEF, nº 69, dez. de 1949, p. 26)

38 A Parte Formativa refere-se a "exercícios construídos, mobilizadores e acentuadamente corretivos da atitude", visando a "formação do corpo"; enquanto que a Parte Aplicada refere-se ao desenvolvimento de características física (da mobilidade, flexibilidade, agilidade, força, entre outras) e psíquicas (coragem, confiança, determinação, entre outras) (RBEF, nº77/78, ago/set. de 1950, p. 5). 
As lições de ginástica sueca estavam divididas em três: Lição de Ginástica Prática ${ }^{\circ} 1$, Lição de Ginástica Prática $n^{\circ} 2$, Lição de Ginástica Prática $n^{\circ} 3$. Em comum, as lições descreviam os movimentos que deveriam ser executados: "corrida com salto em altura batendo em um obstáculo"; "sentido, oscilação antero-posterior de braços com circundução e salto no mesmo lugar"; "pernas afastadas, um braço em elevação lateral e o outro atrás das costas, oscilação do braço em frente do peito (1), oscilação lateral do braço, flexão do tronco com elevação superior do braço e flexão dum joelho (3) insistência (1-4)". Organizado para fazer parte da formação de professores de ginástica, esses exemplos nos mostram uma linguagem técnica e a presença de determinados códigos que exigiam formação para traduzir esses termos empregados atividade. Não muito diferentes dos manuais existentes, que agrupando um conjunto de lições, orientavam a prática ${ }^{39}$.

A segunda, intitulada Ginástica Sueca: exercícios em aparelhos e destreza, foi escrita em coautoria com Lélio Ribeiro ${ }^{40}$.

Os autores desta coletânea de exercícios foram professores da seção latina do curso Internacional de Estocolmo, após a realização da Segunda Lingíada, a qual durou de 7 a 18 de Agosto do corrente ano. (RBEF, no 69, dez. de 1949, p. 35)

Seguindo uma estrutura diferente das lições já apresentadas, os autores organizam o ensino nos seguintes eixos: Saltos; Exercícios na trave; Exercícios dois a dois: e Exercícios de destreza. Cada um desses eixos apresenta dezenas de variações, que possibilita o professor de ginástica combinar diferentes exercícios, montando diferentes lições. Portanto, diferentemente da primeira reportagem que descrevia as lições, nesta encontram-se os grupos de exercícios que precisavam ser combinados para transformarem-se em lições. Exigia-se, assim, um conhecimento mais aprofundado do método sueco, a fim de possibilitar operar com referenciais teóricos que possibilitassem um alinhamento com a progressão pedagógica constituinte do método.

Esses diferentes sujeitos que defendiam a Moderna Ginástica Sueca, nas suas mais diversas formas de apresentar, tinham um ponto em comum: defender que a ginástica sueca que sustentava essa forma moderna de organizar a ginástica, apresentava suas bases na ginástica de Ling. Isso parece ser uma estratégia de utilização da legitimidade que a Ginástica de Ling adquiriu em diferentes regiões do mundo, almejando, continuar garantindo a expansão de sua prática:

Com estes reformadores da ginástica durante as últimas décadas, já há muitas inovações de grande envergadura na ginástica; mas as ideias de Ling seguem sempre sendo a base dos métodos modernos de trabalho. (RBEF, nº 46, Jan. de 1948, p. 42)

Há uma preocupação constante o discurso da manutenção da base de Ling. A adaptação é um termo muito utilizado quando se trata da necessidade de desenvolvimento do método. É

\footnotetext{
39 Alguns manuais circularam no Brasil, como o Manual theorico pratico de gymnastica escolar (1888), de Pedro Manoel Borges, o Compendio de gymnastica escolar - Methodo sueco-belga brasileiro (1896), de Arthur Higgins e o Compendio pratico de Gymnastica - Para uso das escolas normaes e primarias (1897), de Antonio Martiniano Ferreira (MORENO, 2015). A maior parte deles organizado com uma parte introdutória, com uma característica mais teórica, e uma maior parte de caráter prático, caracterizando mais um guia para ser aplicado.

${ }^{40}$ Lelio era Português. Há evidências que esteve na Suécia se especializando no ensino da ginástica. Trabalhou com ginástica no Sporting Clube de Portugal (http://www.sportingcanal.com/?p=4126). Esteve no Brasil na década de 1970, como um dos especialistas convidados para debater a Educação Física Nacional (CUNHA, 2017).
} 
recorrente a intenção de tornar explícita a necessidade de resguardar os princípios da ginástica de Ling, como um a priore.

Aplicando estes princípios fundamentais e também muitas novas experiências de investigações médicas, a ginástica sueca tem se desenvolvido de uma maneira racional e determinada durante as últimas décadas. Isto de tem podido notar especialmente pelo desenvolvimento sensacional da ginástica voluntária na Suécia. Tem-se visto os últimos anos que neste campo se abrem novas e grandes perspectivas para a ginástica como fator cada dia mais necessário ao atual progresso cultural. (RBEF, nº 46, Jan. de 1948, p. 42)

Essa Moderna Ginástica Sueca deixou de ser pensada para um público restrito, passando a ser proposta para grandes grupos, através de um movimento denominado ginástica voluntária. Novo sentido passou a caracterizar essa ginástica, voluntária, do século XX: ginástica para todos, ginástica da saúde e sua aplicação geral. Adaptou-se sua organização, os exercícios e os métodos de trabalho às necessidades de formas adequadas de exercícios recreativos. As salas de ginástica das escolas se transformaram em centros de recreio e a estes centros se buscava atrair um grande público, duas vezes por semana, buscando recreação, alegria, saúde e entretenimento por meio da ginástica. Segundo Holmström, o envolvimento da comunidade foi tamanha, que em uma cidade com 600.000 habitantes, como Estocolmo da década de 1940, havia aproximadamente 500 grupos de ginástica voluntária que se reuniam semanalmente (RBEF, nº 46, Jan. de 1948).

Durante os últimos anos temos visto na Suécia que a situação atual das condições de vida com sua sempre maior especialização e intensificação do trabalho e das condições de trabalho dos indivíduos, abre novas e enormes perspectivas futuras para a ginástica, de acordo com as diretrizes suecas atuais. (RBEF, $\mathrm{n}^{\circ}$ 46, Jan. de 1948, p. 42)

Entre essas novas possibilidades de ginástica, Holmström descreveu a ginástica desportiva, destinada ao treinamento esportivo; a ginástica das Donas de Casa, que se caracteriza como a ginástica para este público; a ginástica para pessoal de oficinas, que se destina a atender as necessidades desse espaço profissional; a ginástica industrial, que tem como público os funcionários das fábricas industriais; a ginástica da família, que propunha uma ginástica matinal de tempo curto; a ginástica de verão, que almejava popularizar a ginástica ao ar livre nas quadras de esporte, praias, etc. (RBEF, no 46, Jan. de 1948, p. 42. Grifo Nosso).

A ginástica das donas de casa é apresentada como uma crescente no país, sendo que em 4 anos, de poucas participantes, passou para 4000 integrantes reunidas em grupos em diferentes partes de Estocolmo (RBEF, $n^{\circ}$ 46, Jan. de 1948, p. 42). A representatividade dessa ginástica aparece na segunda Lingíada, através de uma demonstração de 5.000 donas de casa, entre os 20 e 72 anos, conforme ressalta a reportagem (RBEF, nº 75/76, Jun/jul de 1950).

No trabalho das fábricas e oficinas não era necessária uma lição de 40-45 minutos. A Moderna Ginástica Sueca se adaptara: "no son ejercicios dificiles los que se ejecutan durante estos ocho o diez minutos" (RBEF, no 46, Jan.o de 1948, p. 43). Exercícios fáceis, inclinações laterais, para frente e para trás, movimentos destinados a estender as articulações e músculos mais utilizados no trabalho são os objetivos dessa ginástica. Nas fábricas, param-se as máquinas, empuram-na para os cantos e destinam-se pouco tempo para "ejecutar ejercicios gimnásticos destinados a contrarestar los efectos de un trabajo monótono y fatigante" (RBEF, n 46, Jan. de 1948, p. 43). 
Es un hecho indiscutible, por lo menos en Suecia, que lãs condiciones actuales de vida crean nuevas bases, antes ni sospechada siquiera, para hacer de la gimnasia un factor indispensable en el trabaju destinado al mejoramiento de la salud publica. Em este sentido lês están reservados a los representantes profesionales de todos los países nuevas y grandes tareas. Para este labor, la gimnasia, tal como Ling a creó y sus sucesores la desarrollaron, reúne lãs cualidades especiales que le permitirán realizar un trabajo, cada dia más intenso, con el fin de mejorar el estado de la salud publica en todos los países. (RBEF, no 46, Jan. de 1948, p. 43)

Tendo circulado antes da ocorrência da Lingíada, esse tema tomou forma novamente na RBEF após o evento. Uma reportagem intitulada Para aumentar a Resistência Biológica do nosso operário, retrata uma entrevista de Inezil Penna Marinho, contando suas impressões na Lingíada como representante do Serviço Social da Indústria e do Brasil, no evento, especialmente no que se refere o papel da Educação Física na constituição de uma resistência ao trabalho. A que se considerar sua função de representante do SESI no evento, Inezil aponta o culto pela ginástica diária, a vida ao ar livre, o transporte típico por bicicletas, a alimentação adequada como parte da cultura sueca, que traduz em um "equilíbrio de vida" do operário sueco. A resistência garantida pela Educação Física contribuiu com uma menor ausência do operário no trabalho, em consequência da boa saúde, garantindo um rendimento maior e uma maior lucratividade para a fábrica: "prevenir, melhor do que remediar" (RBEF, nº67/68, Out/Nov de 1949).

Ampliando as possibilidades de tempos e espaços para a Moderna Ginástica Sueca, Austin Souchy apresenta a ginástica sueca no rádio:

Nas manhãs, as mães praticam ginástica com seus filhos ao ritmo musical, escutando vozes de comando do rádio. Para dirigirem-se aos seus trabalhos, homens e mulheres, em grande número, não se servem de caminhões, bondes ou carros, mas sim o fazem a pé para fazer os exercícios. (RBEF, n³1, Out. de 1946, p.16)

Também propõe, como Thulin, que os exercícios para os camponeses não devem ser os mesmos para os operários, assim como devem se diferenciar da ginástica para os sedentários. Segundo ele, "a ginástica, com atitudes mais ou menos estancadas, herança do século passado, está rebaixada hoje pela ginástica rítmica e dinâmica" (RBEF, n³1, Out. de 1946, p.16).

A crítica a essa ginástica rígida, monótona, a "Antiga Ginástica Sueca", é apresentada por Langlade e Langlade (1970) como sendo a peça central para novas propostas do ensino da ginástica. Não apenas uma reformulação interna foi proposta - como protagonizada por Björksten, Bukh, Falk e Thulin, entre outros - mas também por outros pensadores que não atuaram no GCI, como Demeny, George Hébert, Lindhard, entre outros.

Assim, a Moderna Ginástica Sueca é permeada por estas tensões que marcaram os debates internos e externos sobre o desenvolvimento da ginástica, especialmente na Europa, nos fins do século XIX e início do século XX. A RBEF, no Brasil, apresentou entre muitas possibilidades, a Moderna Ginástica Sueca como uma prática capaz de contribuir na educação do corpo do brasileiro, em um momento que o campo da Educação Física estava debatendo a necessidade de um método nacional que desse estivesse alinhado às necessidades do povo brasileiro. 


\section{Considerações Finais}

A Ginástica Sueca, criada no início do século XIX por Ling, passou por reconfigurações, dando forma a uma Moderna Ginástica Sueca que circula no Brasil na primeira metade do século XX. É recorrente a marca da ginástica de Ling nos estudos no campo da história da educação física brasileira, entretanto, pouco se pesquisa e se conhece sobre essa forma de ginástica que circulou por anos em periódicos especializados no país.

A RBEF constituiu-se em lugar de circulação de conhecimentos sobre a Educação Física, divulgando a Moderna Ginástica Sueca como uma prática possível para a educação do corpo. Nas décadas de 1940 e 1950 ocorreram intensos debates sobre a instituição de um método nacional de Educação Física no país, nos quais a adoção ou criação de uma forma de educação o corpo estiveram recorrentemente em cena. Estudar os periódicos especializados da Educação Física que circularam na primeira década do século XX nos ajuda a construir uma versão da história da Educação Física de um período pouco pesquisado.

A Moderna Ginástica Sueca aparece com variações de sessões com tempos específicos segundo o local de execução. Local esse que não ficava mais restrito aos Institutos e salas de ginásticas, mas adentravam as fábricas, oficinas, as casas, procurando nesses espaços contribuir com a aqueles que trabalhavam em posições nocivas à saúde ou que não tinham como sair de casa. Ao chegar nesses lugares, buscava também conquistar um público com uma ginástica que contrapunha a uma ginástica criada por Ling, considerada nesse momento por diferentes intelectuais europeus que estavam envolvidos no debate sobre a ginástica, especialmente vinculado a um conjunto de outras correntes ginásticas que emergiram no final do século XIX e início do século XX, como sendo uma ginástica rígida, anatômica, monótona. Uma nova roupagem foi necessária para a ginástica sueca continuar em cena na disputa por um lugar na educação dos corpos, e circula no Brasil intensificando o debate nacional sobre um método para a Educação Física no país.

\section{Referências}

ANDRIEU, G. La Gymnastique au XIX Siècle ou a naissance de l'education physique (1789-1914). França: Editions Actio, 1999.

ASSUNÇÃO, W. R; SCHNEIDER, O.; SANTOS, W.; FERREIRA NETO, A. A Educação Física, o esporte e o (Pan-)americanismo em revista (1932-1950). Revista da Educação Física (UEM. Impresso), v. 25, p. 1, 2014.

AVELAR, A. C. Uma ginástica que também se lê: a produção do Compendio de Gymnastica Escolar de Arthur Higgins (1896-1934). Dissertação (Mestrado em Educação). Belo Horizonte: FAE/UFMG, 2018.

AZEVEDO, F. Da Educação Physica: o que ella é - a que tem sido - o que deveria ser. São Paulo: Weiszflog editores, 1920.

BAIA, A. C. BONIFÁCIO, I. M. A; MORENO, A. Métodos Ginásticos como campo de disputa na França (1895-1909): Contribuições de Kumlien e Demeny. XX Congresso Brasileiro de Ciências do Esporte e VII Congresso Internacional de Ciências do Esporte, 2017b.

BAIA, A. C.; BONIFACIO, I. M. A.; MORENO, A. O tratado pratico de gymnastica de L. C. Kumlien: circulação, transformação e vestígios do método sueco de ginástica na educação dos corpos no Brasil (1895-1955). In: IX CBHE história da educação: global, nacional e regional. João Pessoa, 2017a, p. 3757-3770. 
BARBOSA, R. Obras completas de Rui Barbosa, v. X --- 1883, t. II --- Reforma do ensino primário e várias instituições complementares da instrução pública. Rio de Janeiro: Imprensa Nacional; 1947.

BERTO, R. C.; SCHNEIDER, O.; FERREIRA NETO, A. A educação da infância nas décadas de 1930 e 1940: representações na Revista Educação Physica. In: XV Congresso Brasileiro de Ciências do Esporte, 2007, Recife - PE. XV CONBRACE e II CONIC - política científica e produção do conhecimento. Recife - PE: CBCE, 2007. p. 1-9.

BRUSCHI, MARCELA; SCHNEIDER, OMAR . As mulheres como autoras: produção e circulação do conhecimento sobre educação física em impressos capixabas (1932-1936). REVISTA BRASILEIRA DE CIÊNCIAS DO ESPORTE, v. 41, p. 116-123, 2019. https://doi.org/10.1016/j.rbce.2018.03.011

BUI-XUÂN, G.; GLEYSE, J. De L'emergence de L'education physique: Georges Demeny et Georges Hébert - um modele conatif aplique au passé. Paris, Hatier, 2001.

CARVAlHO, L. M; CORREIA, A. C. A recepção da Ginástica Sueca em Portugal nas primeiras décadas do século XX: conformidades e dissensões culturais e políticas. Revista Brasileira de Ciências do Esporte, v.37, n.2, 2015, p.136-143. https://doi.org/10.1016/j.rbce.2014.11.018

CASSANI, Juliana Martins. Da imprensa periódica de ensino e de técnicas aos livros didáticos da educação física: trajetórias de prescrições pedagógicas (1932-1960). Cassani Tese (Doutorado em Doutorado em Educação Física) - Universidade Federal do Espírito Santo, 2018.

CUNHA, L. B. A Educação Física Desportiva Generalizada no Brasil: princípios e sistematizações de um método de ensino em circulação (1952-1980). Tese (Doutorado em Educação) Faculdade de Educação, Universidade Federal de Minas Gerais, MG, 2017.

FERREIRA NETO, A. Publicações periódicas de ensino, de técnicas e de magazines em educação física e esporte. In: DACOSTA, L. P. (Org). Atlas do esporte no Brasil. Rio de Janeiro: Shape, 2005. p. 776-777.

FERREIRA NETO, A.; SANTOS, W.; MELLO, A. S.; SOARES, A. J. G; SCHNEIDER, O. Por uma teoria da Educação Física brasileira na imprensa periódica de ensino, técnica e científica. Movimento (UFRGS. Impresso), v.20, 2014, p.1473-1497. https://doi.org/10.22456/1982-8918.46387

FERREIRA NETO, A., SCHNEIDER, O., AROEIRA, K. P., BOSI, F., SANTOS, W. Catálogo de periódicos de educação física e esporte (1930-2000). Vitória: Proteoria, 2002.

GEORGII, A. A Biographical Sketch of the Swedish poet and gymnasiarch, Peter Henry Ling. London, 1854.

GIMÉNEZ, R. R. Una conciencia y un corazón rectos en un cuerpo sano: educación del cuerpo, gimnástica y educación física en la escuela primaria uruguaya de la reforma. In: SCHARAGRODSKY, Pablo. (comp.) La invención del "homo gymnasticus": Fragmentos históricos sobre la educación de los cuerpos en movimiento en Occidente. Buenos Aires: Prometeo, 2011. p. 477- 496. 
GOELLNER, S. V. O método francês e a Educação Física: da caserna à escola. Dissertação (Mestrado em Educação Física). Porto Alegre: UFRGS, 1992.

GÓIS JUNIOR, E. Georges Demeny e Fernando de Azevedo: uma ginástica científica e sem excessos (Brasil, França, 1900-1930). Revista Brasileira de Ciências do Esporte, v. 37, 2015, p. 144-150. https://doi.org/10.1016/j.rbce.2014.11.017

GÓIS JUNIOR, E.; MATTOS, L. Educação do corpo e higiene escolar na imprensa do Rio de Janeiro (1930-1939). Educação e Pesquisa - Revista da Faculdade de Educação da USP, v. 42, p. 411-426, 2016. https://doi.org/10.1590/S1517-9702201606147225

GRUT, T.A. The Gymnastic Central Institute at Stockholm. In: International Congress on School Hygiene. Buffalo, 1913.

HAGELIN, O. Rare and Curious Books in the Library of the old Royal Central Institute of Gymnastics. Estocolmo, 1995.

HOLMSTRÖM, A. La Moderna Gimnasia Sueca - desde Ling hasta la Lingíada. Editorial Sohlman, Estocolmo, Suécia, 1949.

JUBÉ, C. N. Educação, Educação Física e Natureza na obra de Georges Hébert e sua recepção no Brasil. (1915-1945). Tese (Doutorado em Educação) Faculdade de Educação, Universidade Estadual de Campinas, SP, 2017.

LANGLADE, A; LANGLADE, N.R. Teoria general de la gimnasia. Buenos aires: Editorial Stadium, 1970.

LEONARD. F. E. A guide to the history of physical education. Lea \& Febiger: Philadelphia e New York, 1923.

LINDROTH, J. Linganism and the natural method - the problem of continuity in Swedish gymnastics. In: 8th International Congress for the History of Sport and Physical Education. Uppsala e Estocolmo, 1979.

LING, P. H. Gymnastikens allmänna grunder. Upsala: Palmblad \& Comp; 1834-1840.

LJUNGGREN, J. ?Por qué la gimnasia de Ling? El desenrrollo de la gimnasia sueca durante el siglo XIX. In: In: SCHARAGRODSKY, Pablo. (Org.) La invención del "homo gymnasticus": Fragmentos históricos sobre la educación de los cuerpos en movimiento en Occidente. Buenos Aires: Prometeo, 2011. p. 37-52.

LUNDVALL, S. From Ling Gymnastics to Sport Science: The Swedish School of Sport and Health Sciences, GIH, from 1813 to 2013. The International Journal of The History of Sport. [s.1.], abr. 2015, p. 789-799. https://doi.org/10.1080/09523367.2015.1023191

MARINHO, Inezil Penna. História da educação física e desportos no Brasil. São Paulo: Companhia Brasil Editora, S/D.

MARINHO, I. P. Sistemas e Métodos de Educação Física. 2. ed. São Paulo: Companhia Brasil Editora, 1958. 
MELO, V. A.; PERES, F. F. A Gymnastica no tempo do Império. 1. ed. Rio de Janeiro: 7 Letras, 2014.

MORAES E SILVA, Marcelo; FONTOURA, Mariana Purcote . Educação do corpo feminino: um estudo na RBEF (1944-1950). RBEF e Esporte (Impresso), v. 25, p. 263-275, 2011. https://doi.org/10.1590/S1807-55092011000200008

MORAES, S. L.; GÓIS JUNIOR, Edivaldo. Teorias sobre a propagação da febre amarela: um debate científico na imprensa paulista, 1895-1903. História, Ciências, Saúde-Manguinhos (Online), v. 22, p. 687-704, 2015. https://doi.org/10.1590/S0104-59702015000300002

MORENO, A. Corpo e ginástica num Rio de Janeiro - mosaico de imagens e textos. Tese (Doutorado em Educação) - Universidade Estadual de Campinas, Campinas, 2001.

MORENO, A. O Rio de Janeiro e o corpo do homem fluminense: o "não-lugar" da ginástica sueca. Revista Brasileira de Ciências do Esporte. 25 (1), 55-68, 2003.

MORENO, A. A propósito de Ling, da ginástica sueca e da circulação de impressos em língua portuguesa. Revista Brasileira de Ciências do Esporte, v.37, 2015, p.128-135. https://doi.org/10.1016/j.rbce.2014.11.019

MORENO, A.; BAÍA, A.C. Do Instituto Central de Ginástica (GCI) de Estocolmo para o Brasil: cultivo e divulgação de uma educação do corpo. Educação em Revista, v. 35, e217636, 2019. Acessos em 12 dez. 2019. https://doi.org/10.1590/0102-4698217636

PEREIRA, C. F. M. Tratado de Educação Física - Problema Pedagógico e Histórico. - Vol I. Lisboa: Bertrand, S/d.

POSSE, N. F. How gymnastics are taught in Sweden: the chief characteristics of the Swedish system of gymnastics - two papers. Boston: T.R. Marvin \& Son; 1891 (reimpressão).

PUBLIO, N. S; CATALANO, I. M. Escola de Educação Física da Polícia Militar do estado de São Paulo. In: DACOSTA, L. (ORG.). Atlas do esporte no Brasil. Rio de Janeiro: CONFEF, 2006, p. 414-415.

PUCHTA, D. R. A escolarização dos exercícios físicos e os manuais de ginástica no processo de constituição da Educação Física como disciplina escolar (1882-1926). Tese (Doutorado em Educação) - Universidade Federal de Minas Gerais, Belo Horizonte, MG, 2015.

QUITZAU, E. A. “A ginástica alemã”: aspectos da obra de Friedrich Ludwig Jahn. Revista Brasileira de Ciências do Esporte. 36 (2), p.501-514, 2014.

QUITZAU, E. A. Da 'Ginástica para a juventude' a 'A ginástica alemã': observações acerca dos primeiros manuais alemães de ginástica. Revista Brasileira de Ciências do Esporte, 37 (2), 111-118, 2015. https://doi.org/10.1016/j.rbce.2015.02.005

QUITZAU, E. A. Associativismo ginástico e imigração alemã no Sul e Sudeste do Brasil (18581938). Tese (Doutorado em Educação). Universidade Estadual de Campinas. Campinas, 2016.

QUITZAU, E. A. ; SOARES, C. L. . Um manual do século XVIII: culto à natureza e educação do corpo em "Ginástica para a Juventude, de Guts Muths". Revista Brasileira de História da Educação, v. 16, 2016, p. 23-50. 
QUITZAU, E. A; MORENO, A.; BAÍA, A. C. Entre traduções e apropriações: reflexões sobre a circulação e recepção dos métodos ginásticos na Alemanha e no Brasil. In: LINHALES; $M$. A; PUCHTA, D. R; ROSA, M. C (Orgs). Diálogos transnacionais na história da educação física. Belo Horizonte: Fino Traço, 2019.

RAMOS, J. J. Os Exercícios Físicos na História e na Arte: do homem primitivo aos nossos dias. São Paulo: IBRASA, 1982.

RAMOS, J. J. A moderna ginástica sueca. Revista de Educação Física, Rio de Janeiro, ano XIX, n. 69, p. 7-9, abr. 1952.

RETZ, R.P.C.; FERREIRA NETO, A.; CASSANI, J.M.; SANTOS, W. Imagens na imprensa periódica de ensino e de técnicas da Educação Física e Esporte (1932-1960). Movimento, v.25, p.1-16, 2019. https://doi.org/10.22456/1982-8918.75040

ROMÃO, A.L.F.; MORENO, A. Das piruetas aos Saltos: As diferentes manifestações da Gymnastica no Rio de Janeiro da Segunda Metade do XIX. Cadernos Cedes (IMPRESSO), v.38, 2018, p.21-32. https://doi.org/10.1590/cc0101-32622018178336

SARREMEJANE, P. L'heritage de la méthode suédoise d'education physique em France: les conflits de méthode au sein de l'Ecole normale de gymnastique et d'escrime de Joinville au début du XXème siècle. Revista Paedagogica Historica, v.42, n.6, 2006, p.817-837. https://doi.org/10.1080/00309230600929559

SCHARAGRODSKY, P. La constitución de la educación física escolar en la Argentina. Tensiones, conflictos y disputas con la matriz militar en las primeras décadas del siglo XX. In: SCHARAGRODSKY, Pablo. (comp.) La invención del "homo gymnasticus": Fragmentos históricos sobre la educación de los cuerpos en movimiento en Occidente. Buenos Aires: Prometeo, 2011. p. 441-475.

SCHNEIDER, O. Entre a correção e a eficiência: mutações no significado da Educação Física nas décadas de 1930 e 1940 - um estudo a partir da revista Educação Physica. Revista Brasileira de Ciências do Esporte, Campinas, v. 25, n.2, p. 39-54, 2004.

SCHNEIDER, O; BRUSCHI, M; SANTOS, W; FERREIRA NETO, A. A Revista de Educação no governo de João Punaro Bley e a escolarização da Educação Física no Espírito Santo (19341937). Revista Brasileira de História da Educação, v.13, p.43-68, 2013. https://doi.org/10.4322/rbhe.2013.014

SOARES, C.L. Educação Física: Raízes Europeias e Brasil. Campinas, SP: Autores Associados, 1994.

SOARES, C.L. Da arte e da ciência de movimentar-se: primeiros momentos da Ginástica no Brasil. In: DEL PRIORE, M., \& MELO, V. A. (Org.). História do Esporte no Brasil: do Império aos dias atuais (p. 133-178). São Paulo: Editora da Unesp, 2009.

SOARES, C.L. Uma educação pela natureza: o método de educação física de Georges Hébert. Revista Brasileira de Ciências do Esporte, v.37, 2015, p.151-157. https://doi.org/10.1016/j.rbce.2014.11.016 
SOARES, C.L.; MORENO, A. Dossiê - Práticas e prescrições sobre o corpo: a dimensão educativa dos métodos ginásticos europeus. Revista Brasileira de Ciências do Esporte, v.37, 2015, p.108-110. https://doi.org/10.1016/j.rbce.2015.03.001

WESTERBLAD, C. A. Ling, the founder of Swedish gymnastics: his life, his work, and his importance. Stockholm: Kungl. Boktryckeriet; 1909.

\section{Fontes}

DA SUÉCIA. Revista Brasileira de Educação Física, Rio de Janeiro, ano 6, n. 67/68, p.51, out./nov. 1949.

HOLMSTRÖM, Agne. La gimnasia de ling como base racional de la moderna educación física. Revista Brasileira de Educação Física, Rio de Janeiro, ano 6, n. 61-62, p. 15-18, abr./maio 1949.

HOLMSTRÖM, Agne. La ginasia de Ling como base racional de la moderna educación física. Revista Brasileira de Educação Física, Rio de Janeiro, ano 5, n. 46, p. 39-43, jan. 1948.

JOHANSSON, Curt. Ginástica para homens: lições de ginástica sueca. Revista Brasileira de Educação Física, Rio de Janeiro, ano 6, n. 69, p. 26-27, dez. 1949.

JOHANSSON, Curt; RIBEIRO, Lelio. Ginástica Sueca: Exercícios em aparelhos e de destreza. Revista Brasileira de Educação Física, Rio de Janeiro, ano 6, n. 69, p. 35-36, dez. 1949.

MAYNE, Magdalena E. B. de. O sistema sueco baseado na ginástica de Ling, adaptado ao sexo feminino, na Argentina. Tradução de Eunice Galvão Antunes. Revista Brasileira de Educação Física, Rio de Janeiro, ano I, n. 2, p. 39-41, fev. 1944.

SOUCHY, Austin. Suécia, mãe da ginástica. Revista Brasileira de Educação Física, Rio de Janeiro, ano 3, n. 31, p. 15-17, out. 1946.

THULIN, J. G. O esquema da lição de ginástica.Revista Brasileira de Educação Física, Rio de Janeiro, ano VII, n. 74, p. 8-10, maio 1950.

THULIN, J. G. O esquema da lição de ginástica.Revista Brasileira de Educação Física, Rio de Janeiro, ano VII, n. 75/76, p. 4-5, jun./jul. 1950.

THULIN, J. G. O esquema da lição de ginástica. Revista Brasileira de Educação Física, Rio de Janeiro, ano VII, n. 77/78, p. 4-5, ago./set. 1950. 